\title{
Phytotoxicity of Ag nanoparticles prepared by biogenic and chemical methods
}

\author{
Rupasree Choudhury ${ }^{1}$ - Manna Majumder ${ }^{1}$ Dijendra Nath Roy $^{2}$. \\ Srijita Basumallick $^{1} \cdot$ Tarun Kumar Misra ${ }^{1}$
}

Received: 16 July 2015/Accepted: 17 June 2016/Published online: 25 June 2016

(c) The Author(s) 2016. This article is published with open access at Springerlink.com

\begin{abstract}
Silver nanoparticles (Ag NPs) are now widely used as antibacterial and antifungal materials in different consumer products. We report here the preparation of $\mathrm{Ag}$ NPs by neem leaves extract (Azadirachta) reduction and trisodium citrate-sodium borohydride reduction methods, and study of their phytotoxicity. The nanoparticles were characterized by UV-Vis spectroscopy, FTIR, and atomic force microscopy (AFM) techniques. Both neem-coated and citrate-coated Ag NPs exhibit surface plasmon around $400 \mathrm{~nm}$, and their average sizes measured by AFM are about 100 and $20 \mathrm{~nm}$, respectively. Antibacterial and antifungal activities of these nanomaterials have been studied by simple pea seed germination and disk diffusion methods. It has been observed from the growth of root and shoot, citrate-coated Ag NPs significantly affect seedling growth, but neem-coated Ag NPs exhibit somehow mild toxicity toward germination process due to the nutrient supplements from neem. On the other hand, antifungal activity of neem-coated $\mathrm{Ag}$ NPs has been found much higher than that of citrate-coated Ag NPs due to the combined effects of antifungal activity of neem and Ag NPs. Present research primarily indicates a possible application of neem-coated Ag NPs as a potential fungicide.
\end{abstract}

Srijita Basumallick

srijitabasumallick@gmail.com

$\bowtie$ Tarun Kumar Misra tkmisra70@yahoo.com

1 Department of Chemistry, National Institute of Technology, Agartala 799046, Tripura, India

2 Department of Bioengineering, National Institute of Technology, Agartala 799046, Tripura, India
Keywords Ag nanoparticles $\cdot$ Neem (Azadirachta indica) . Seed germination $\cdot$ Antifungal effect

\section{Background}

Due to their potential antibacterial and antifungal activities, silver nanoparticles are now widely used $[1,2]$ in various consumer products. These products range from pharmaceuticals, such as wound dressings, toothpaste, and tissue papers, to textile goods. After the end uses, these nanoparticles are inevitably discharged to the environment, and pollute water bodies and soil. This leads to an increasing interest in research on phytotoxicity and ecotoxicity of $\mathrm{Ag}$ nanoparticles. Major phytotoxicity studies use a seed germination technique. Majumder et al. reported [3] phytotoxicity of Ag nanoparticles on seeds, such as rice, mustard, and green gram. These authors have discussed the uptake of Ag nanoparticles by different tissues of the seed from atomic absorption spectroscopy studies (ASS). The decrease in root length with increase in silver concentration has been reported. In several studies [4, 5], it has been shown that cell wall act as sieve, which allows only small particle to enter into protoplasm [5]. Silver nanoparticles up to $20 \mathrm{~nm}$ may be transported through plasmodesmata and flow through xylem to reach the shoot. Therefore, it is quite unlikely that there will be pronounced toxicity in shoot by silver nanoparticles. Even in the case of silver ion-mediated toxicity at low concentrations, silver ion accumulates evenly throughout the whole plant, but at higher concentrations, $\mathrm{Ag}$ accumulation increases in the plant roots, and it is poorly translocated to the shoots [5].

Neem (Azadirachta indica) leaf is a potent antifungal and antibacterial [4] agent. The major advantage of using neem (A. indica) leaf as capping as well as reducing agent 
in preparing neem-coated silver nanomaterial is that it is easily available and eco-friendly. Extracts of neem contain major ingredients, such as reducing sugar, flavonoid, terpenoid, and pigments [5]. These components are known for their antibacterial and antifungal properties $[6,7]$. Due to its low cost as well as biocompatibility, neem extract is used as pesticide in agricultural field [8]. Azadirachtin, a tetranortriterpenoid, is the main active component of neem, which contains other active substances, such as salanin, epoxiazadiradione, meliantrol, melianone, gedunin, nimboline, nimbin, deacetilasalanin, azadiractol, azadirone, vilosinin, and meliacarpine, and over 300 characterized components [9-12]. Azadirachtin provides repellent, antihormonal, and antifeedant properties. Neem leaf works as pesticide by inhibiting enzyme activities of insects which govern growth [8, 9] of insects. Three major enzymes, namely, prothoracicotropic hormone (PTTH), juvenile, and ecdysone [13], play an important role for the growth. Among these, ecdysone and other steroid-based enzymes in endocrine get inhibited by Azadirachtin [6]. On the other hand, sodium nimbinate provides diuretic, spermicidal, and antiarthritic properties [14]. Again, neem extract may be used as fertilizer [15], and its biodegradation is a potential source of nitrogen [16-18].

Present study aims to compare phytotoxicity of Ag NPs prepared by chemical route and biogenic route (using neem extract) by the pea seed germination method, and antifungal property on Aspergillus sp. by the disk diffusion method to explore their application potential.

\section{Results and discussions}

Several studies [2, 19-22] have been reported on neemcoated silver nanoparticles to understand their antibacterial properties. Flavones, organic acids, and quinones are water-soluble phytochemicals present in neem extract, and these are responsible for the reduction of silver ions [19]. Figure 1 shows UV-Vis spectra of citrate-coated Ag NPs (red line), neem-coated Ag NPs (blue line), and aqueous extract of neem (black line). Characteristic plasmon resonance peaks at 380 and $450 \mathrm{~nm}$ of $\mathrm{Ag}$ nanoparticles are seen in these spectra. Plasmon resonance peak depends on the particle sizes, and the observed peak at $560 \mathrm{~nm}$ is due to the presence of prism-shaped silver nanoparticle [23]. To regulate particle size of citrate-coated Ag NPs, the NPs solution was kept in warm condition when these prismshaped particles were formed consequently, and an additional UV-visible peak appeared. However, an average citrate-coated Ag NPs appear to be smaller in size compared with neem-coated Ag NPs.

Figure 2 shows the formation of Ag NPs at different times upon addition of aqueous extract of neem leaves on

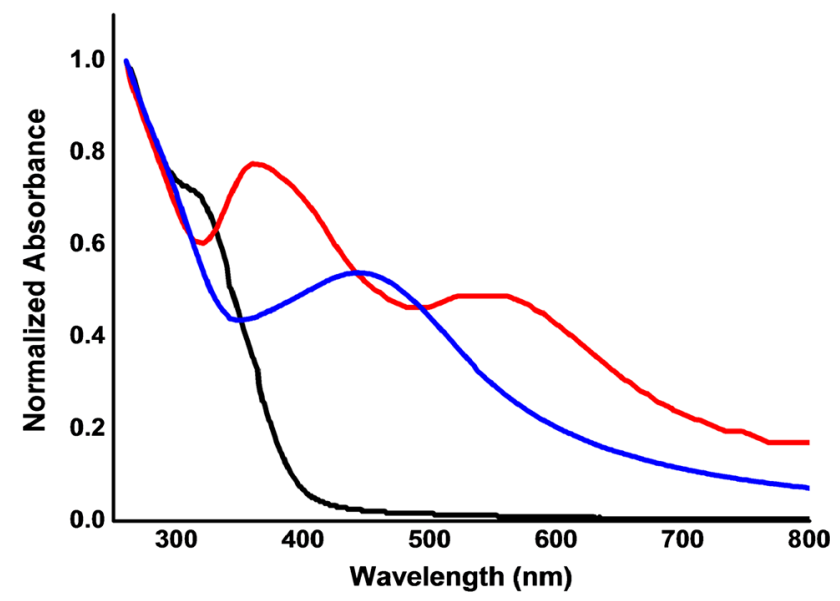

Fig. 1 UV-visible spectra of citrate-coated Ag NPs (red), neemcoated Ag NPs (blue), and neem leaves extract (black)

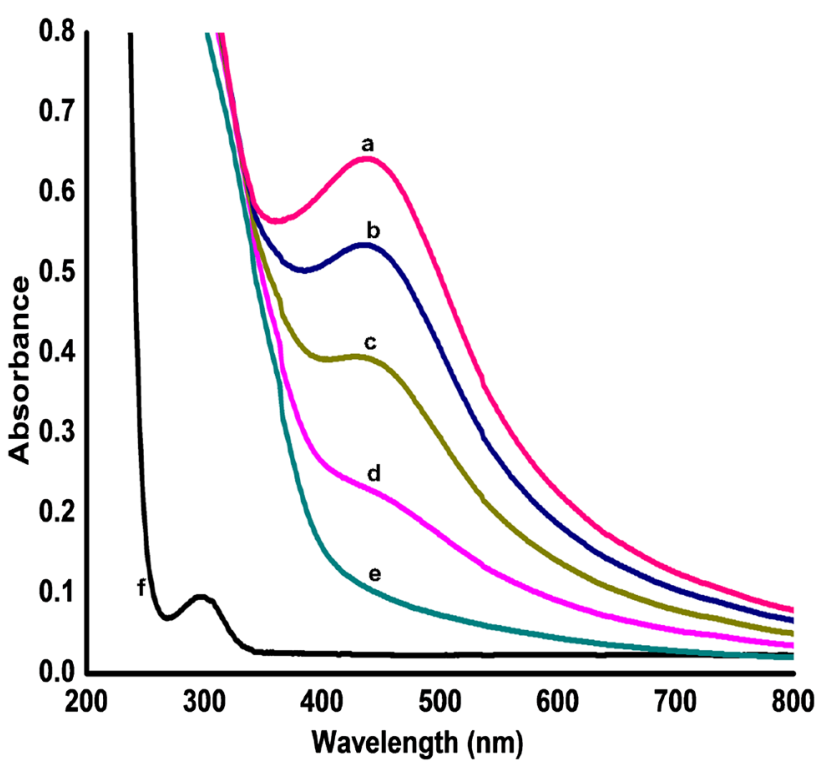

Fig. 2 UV-visible spectra of neem-coated Ag NPs in different times (a) $40 \mathrm{~min}$, (b) $30 \mathrm{~min}$, (c) $25 \mathrm{~min}$, (d) $15 \mathrm{~min}$, (e) $0 \mathrm{~min}$, and (f) $\mathrm{AgNO}_{3}$ solution

$\mathrm{AgNO}_{3}$ solution under warm condition. Characteristics peaks of Plasmon resonance spectra of Ag NPs around $400 \mathrm{~nm}$ are seen in these figures, and they are absent with dilute aqueous extract of neem and $\mathrm{AgNO}_{3}$ solutions.

Fluorescence spectra of dilute aqueous extract of neem leaves and neem-coated Ag NPs are shown in Fig. 3. There is no shift in emission maxima, indicating that the fluorophore present in aqueous extract of neem is adsorbed onto neem-coated Ag NPs.

Figure 4 shows FTIR spectra of neem leaf extract and neem-coated Ag NPs to identify the possible biomolecules responsible for capping and stabilization of Ag NPs. FTIR spectrum analysis indicates the presence of active 


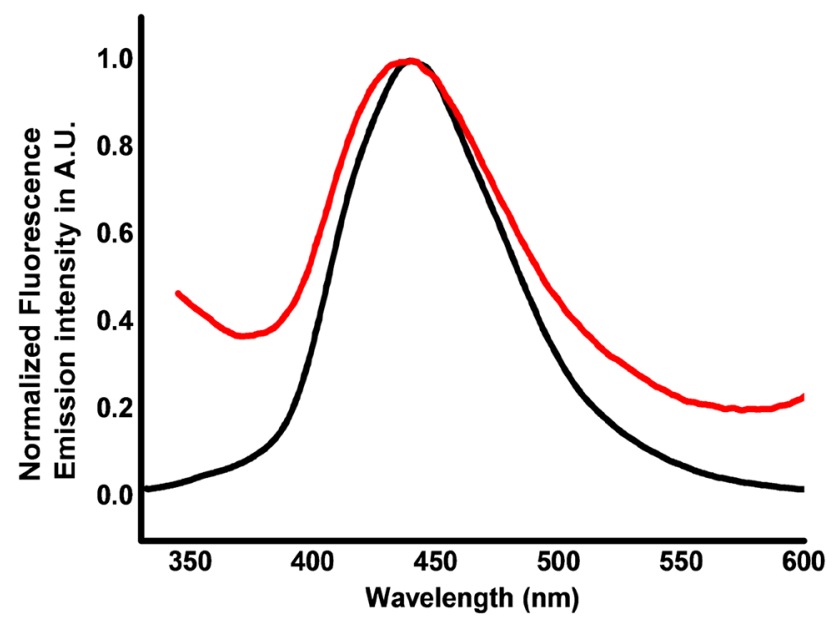

Fig. 3 Fluorescence emission spectra of neem leaf extract (black line) and neem-coated Ag NPs (red line) at $\lambda_{\mathrm{ex}}=318 \mathrm{~nm}$

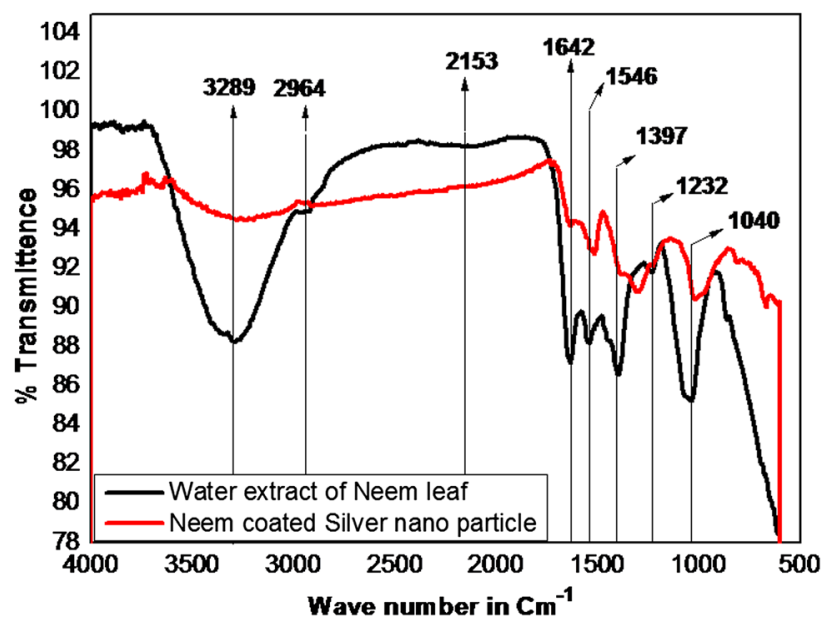

Fig. 4 Fourier transform infrared spectra of neem leaf extract (black line) and neem-coated Ag NPs (red line)

functional groups in the synthesized silver nanoparticles. The peaks observed at 3289 and 2964 correspond to $\mathrm{O}-\mathrm{H}$ and $\mathrm{C}-\mathrm{H}$ stretching frequency, respectively. The assignment at 1642 corresponds to $\mathrm{C}=\mathrm{O}$ group. The peak at 1040 might be contributed to the presence of methoxy group. From the analysis of FTIR studies, it has been proved that carboxyl $(-\mathrm{C}=\mathrm{O})$, and methoxy groups are mainly involved in silver nanoparticles capping.

Figure 5 shows AFM images of citrate-coated Ag NPs and neem-coated Ag NPs. It is seen with small ion (citrate) that acts as capping agent, capping reaction is fast, and we obtain smaller sizes 20 -to-100-nm particles. However, with large organic molecules from neem extract, the capping reaction is relatively slow producing particles of $90-120 \mathrm{~nm}$.

Figure 6 shows morphology of seed germination pattern of pea seeds kept under four different conditions, water, citrate-coated Ag NPs solution, neem extracts, and neemcoated Ag NPs solutions. It may be mentioned that almost all the seeds germinate kept in water, citrate-coated $\mathrm{Ag}$ NPs (20 nm diameter) solution, aqueous extract of neem leaf, and neem-coated Ag NPs $(\sim 100 \mathrm{~nm})$. This may be due to the fact that Ag NPs cannot penetrate [24] the outer coatings of the seed and do not have any considerable effect on initial germination process $[24,25]$.

Looking at the shoot growth pattern, it appears that citrate-coated Ag NPs show acute toxicity as there is practically no sign of shoot growth, and some black patches appear on the skin of seed. Similar effect has been seen in other species also like Chlamydomonas reinhardtii algae and Cucurbita pepo [26-30] at Ag NPs diameter of about $40 \mathrm{~nm}$. It is reported [29, 30], Ag NPs impaired the stages of cell division and caused cell disintegration. Yin et al. [28] have shown that root cells accumulate most of the Ag NPs in the plants, and the translocation factor (Ag in shoot/Ag in root) is very low. In some cases, it is seen that NPs penetrate cell wall and plasma membranes of epidermal layers in roots to enter vascular tissues [4]. This causes strong root responses in the presence of NPs. We observed similar effect of acute cytotoxicity with citrate-coated Ag $(20 \mathrm{~nm})$ NPs.

The observed promoting effect of both root and shoot growths in the case of neem-coated Ag NPs $(100 \mathrm{~nm})$ is apparently anomalous. Aqueous extract of neem leaves promotes (third one in the figure) seedlings growth due to the nutritional effect [7] of sugars and water-soluble aminoacids/proteins present in the extract. Promoting effect of NPs on root growth and chlorophyll content of seedlings of Brassica juncea has been reported [31] and explained in terms of improved antioxidant status. However, in this study, we observed seedlings promotional effect with neem-coated Ag NPs, which is possibly due to nutritional supplements of neem leaves extract. Figures 7 and 8 are bar diagrams representing root and shoot lengths obtained from analysis of morphological changes, as shown in Fig. 6 using the literature protocols [32]. We have also assessed chlorophyll contents of the treated seedlings with differently coated Ag NPs and observed (Fig. 9) similar promotional effect with neem coatings.

The present study also extended to compare the antifungal activity of aqueous extract from neem leaves, citrate-coated Ag NPs, and neem-coated Ag NPs against an important pathogen Aspergillus sp. The results are shown in Fig. 10. It is interesting to note that neem-coated Ag NPs show an excellent antifungal activity toward this pathogen owing to synergistic effect of antifungal activity of Ag NPs and aqueous extract of neem leaves. From the antifungal study, it is seen that neem-coated Ag NPs exhibit better growth inhibition of this fungus compared with citratecoated Ag NPs or aqueous extract of neem alone. In Fig. 11, the effect of these NPs is assessed by measuring of 

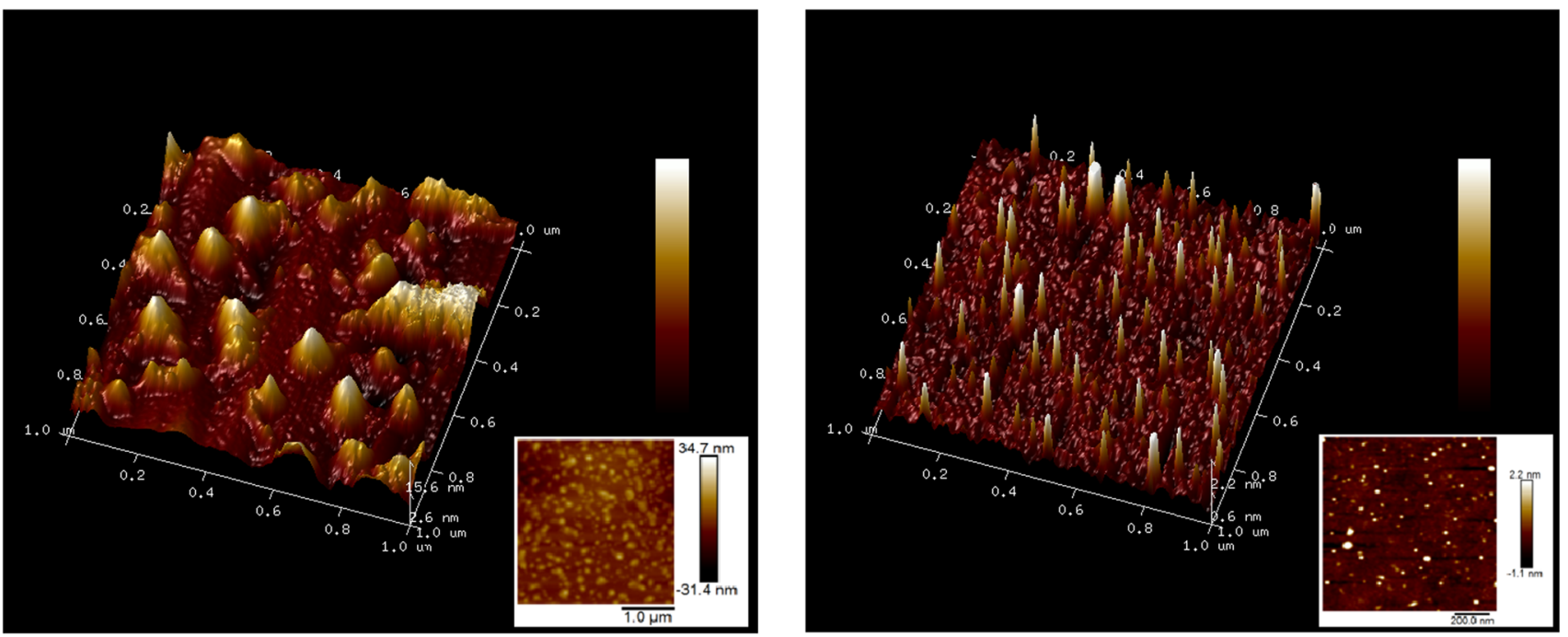

Fig. 5 AFM image (3D) of neem-coated Ag NPs (left) and 2-D (left bottom inset), citrate-coated Ag NPs 3-D (right), and 2-D (right bottom inset)

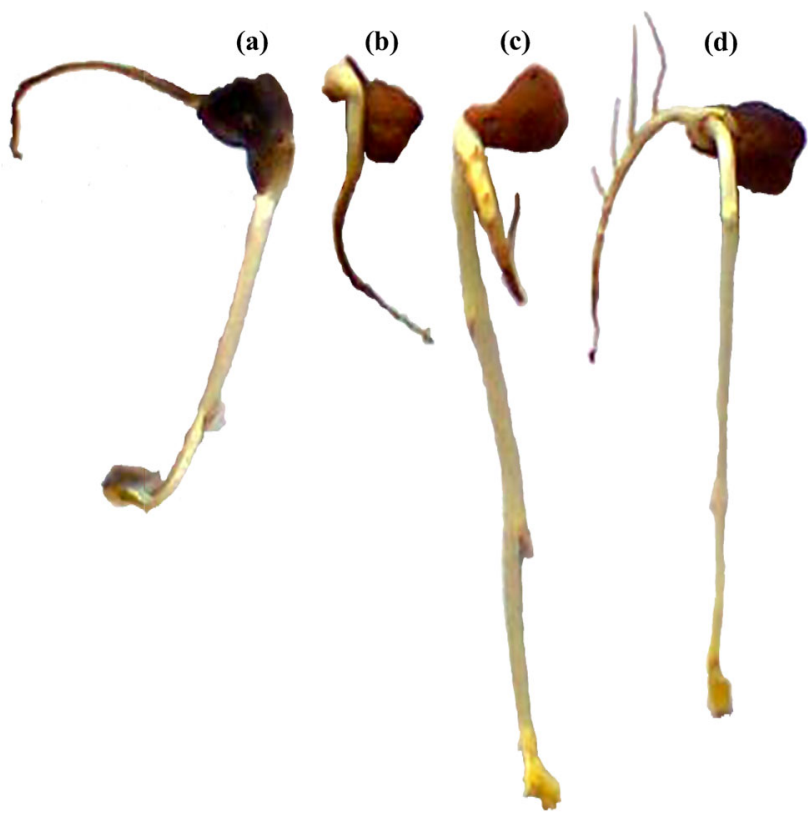

Fig. 6 Morphology of chickpea (Cicer arietinum) in aqueous dispersions of (a) neem-coated Ag NPs, (b) citrate-coated Ag NPs, (c) in water, and (d) in aqueous extract of neem leaves, after 7 days

diameter of zone of inhibition. Interestingly, it is found (Fig. 11) that increasing the concentration of NPs enhances the diameter of zone of inhibition.

\section{Materials and methods}

All chemicals used in this study were of analytical reagent grade and were used without further purification. Silver nitrate $\left(\mathrm{AgNO}_{3}\right)$, sodium borohydride $\left(\mathrm{NaBH}_{4}\right)$, and

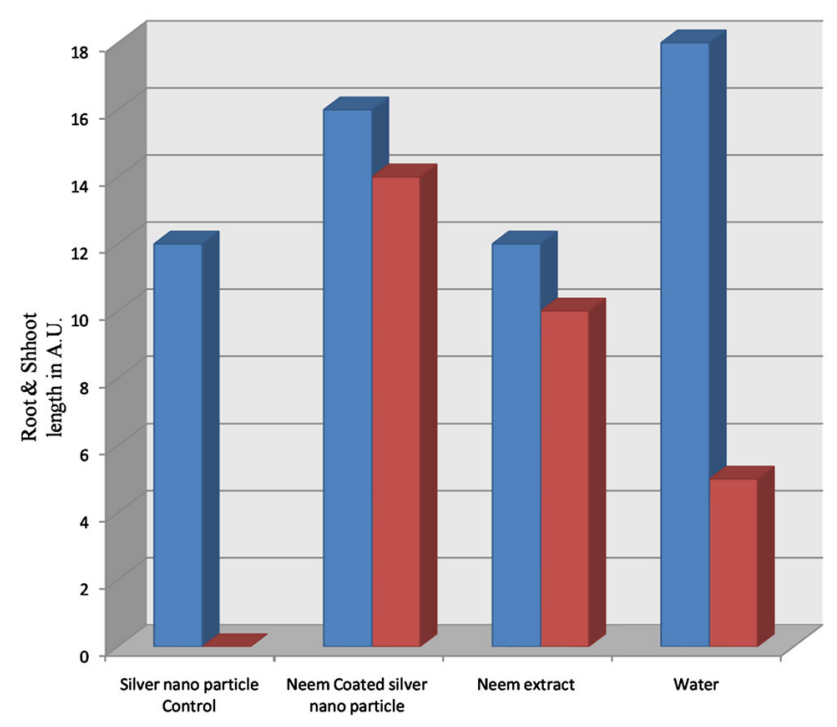

Fig. 7 Bar diagrams of Root length in different samples and Shoot length in different samples

Trisodium citrate were purchased from Sigma-Aldrich. Ethanol and $\mathrm{HCl}$ were purchased from Merck and used as received. Double-distilled water was used for preparation and spectroscopic studies. All the glassware was washed thoroughly with distilled water and dried in an oven. Neem leaves were collected from a mature neem tree in Agartala, Tripura. Neem (A. indica) leaf extract was prepared in double distilled water. AFM was recorded in Bruker Multimode instrument equipped with NanoScope 8, and the data were collected in tapping mode on a glass substrate. 


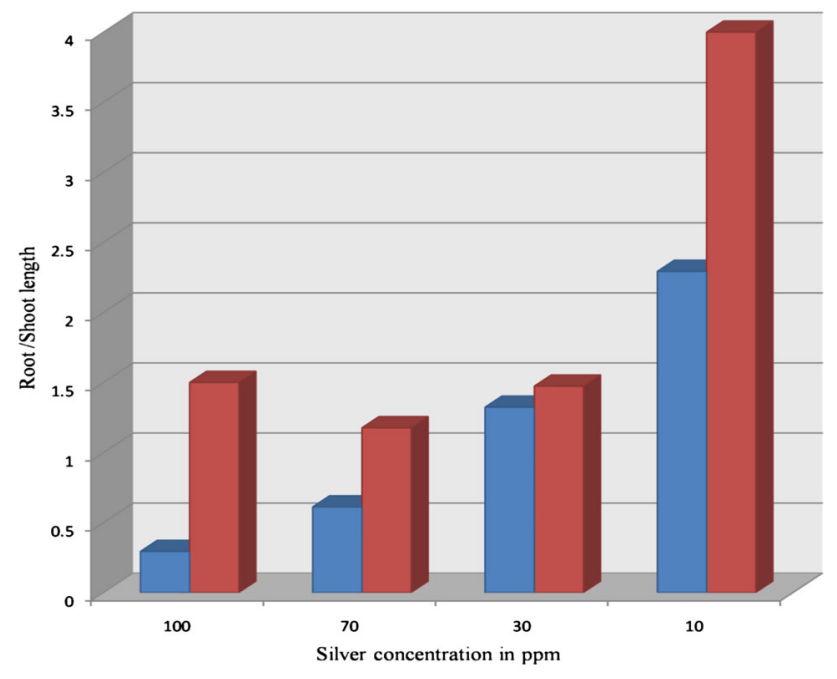

Fig. 8 Bar diagrams of Root/shoot length in Ag NPs control and Root/shoot length in neem-coated Ag NPs

\section{Measurements}

The electronic absorption spectra of the materials were recorded in the region 1100-200 $\mathrm{nm}$ using a Shimadzu UV-Vis-1800 spectrophotometer with a quartz cell of 1.0$\mathrm{cm}$ path length. The atomic force microscopy image was taken in taping mode in a Bruker Nano Scope 8 machine with spring constant $40 \mathrm{~N} / \mathrm{m}$. Fluorescence spectra were recorded using a Perkin Elmer L S 55 Spectrofluorometer in the range of 330-600 $\mathrm{nm}$. Unicom rectangular water bath was used for reaction as well as concentrating various samples to their desired value.

\section{Preparation of silver nanoparticles}

Silver nanoparticle control was prepared by following the literature protocol [18]. Briefly, a solution of $\mathrm{NaBH}_{4}$ $(0.01 \mathrm{M})$ and a separate solution of $\mathrm{AgNO}_{3}(0.01 \mathrm{M})$ were prepared, and $0.2-\mathrm{mg}$ trisodium citrate was weighed in a beaker containing $44 \mathrm{ml}$ of ice cooled DD water in an ice bath. Then, $45 \mathrm{ml}$ of $0.01-\mathrm{M} \mathrm{NaBH} 4$ was added under stirring condition, and successively, trisodium citrate solution was mixed. After $20 \mathrm{~min}$ of stirring at ice bath, $2 \mathrm{ml}$ of 0.01-M $\mathrm{AgNO}_{3}$ was added drop by drop (one drop per sec). After addition, the electronic absorption spectra of the yellow solution were taken at the range of $200-800 \mathrm{~nm}$.

\section{Preparation of neem extract}

Fresh leaves of $A$. indica were collected from a mature neem tree in Agartala, Tripura and washed several times with water to remove the dust particles and then sun dried to remove the residual moisture and grinded to form
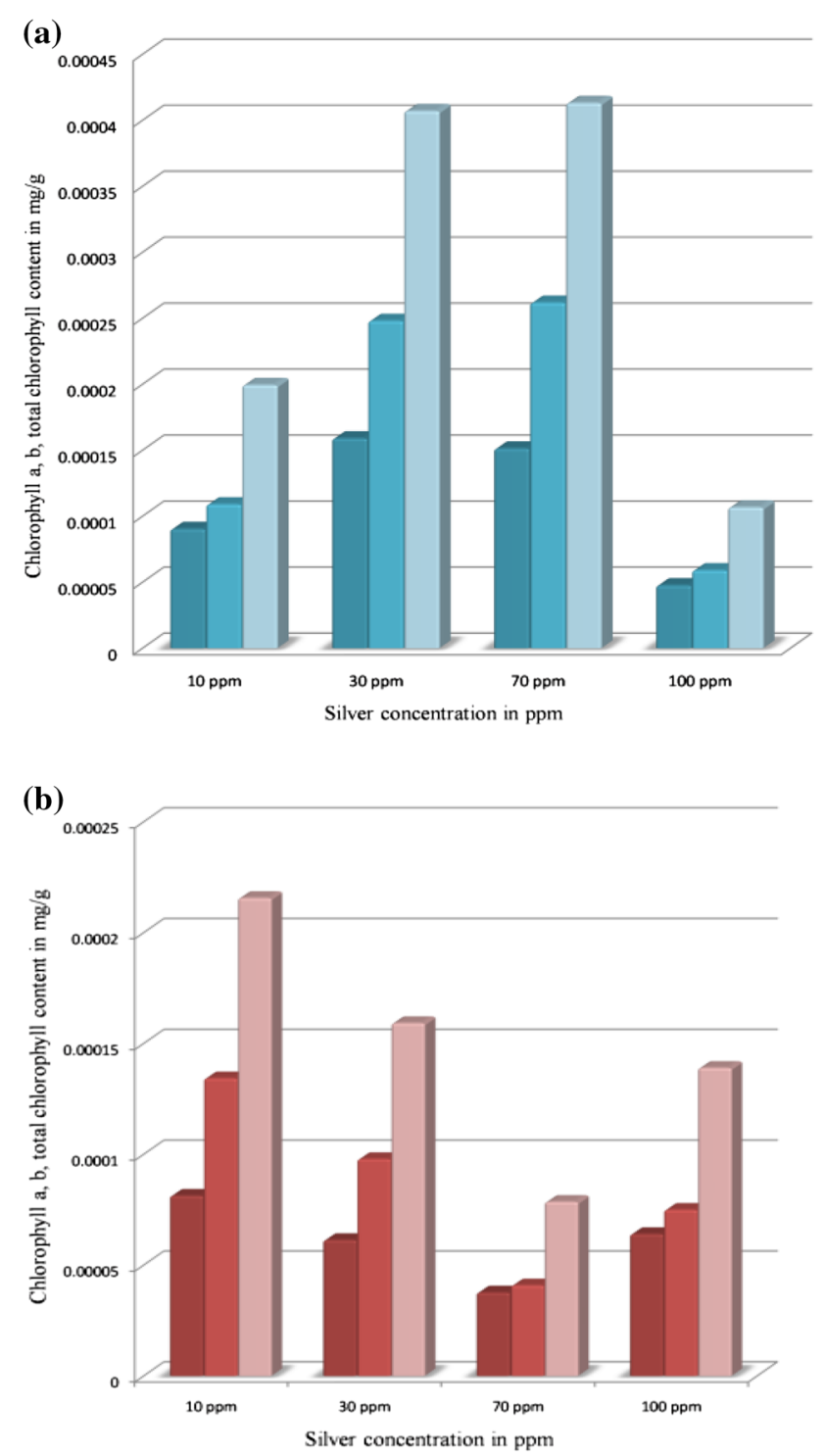

Fig. 9 Bar diagrams of a Chlorophyll-a for neem-coated Ag nano, Chlorophyl-b for neem-coated Ag nano, Total chlorophyll in neem-coated $\mathrm{Ag}$ nano and b Chlorophyl-a for Ag nano control, Chlorophyll-b for Ag nano control, Total chlorophyll in Ag control

powder. The powder $(1 \mathrm{~g})$ was soaked in $7 \mathrm{ml}$ of distilled water and kept for $24 \mathrm{~h}$, after that the solution was filtered. Then, $2.04 \mathrm{ml}$ of distilled water was added to the $1 \mathrm{ml}$ of filtrate. This extract was again diluted 10th time by distilled water, and the diluted extract was used for the synthesis of neem-coated silver nanoparticles.

\section{Preparation of neem-coated silver nanoparticles}

For the synthesis of neem-coated silver nanoparticles, $1 \mathrm{ml}$ of neem extract was added to $4 \mathrm{ml}$ of $0.01-\mathrm{M} \mathrm{AgNO}_{3}$ solution. The mixture was heated at $60{ }^{\circ} \mathrm{C}$ on water bath 


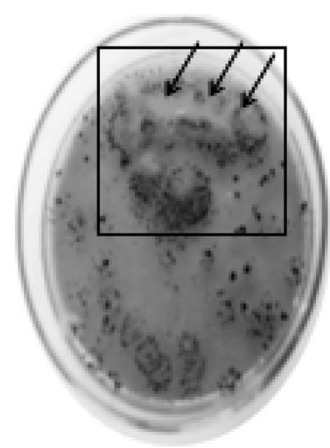

SNP + Neem

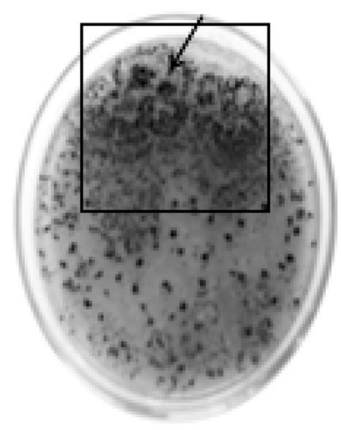

Neem

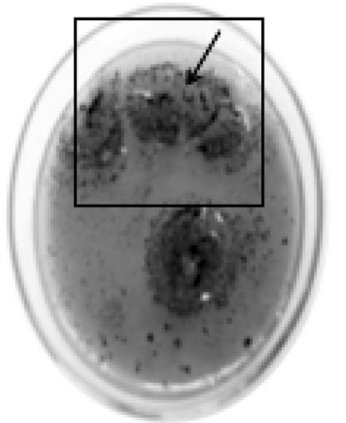

SNP

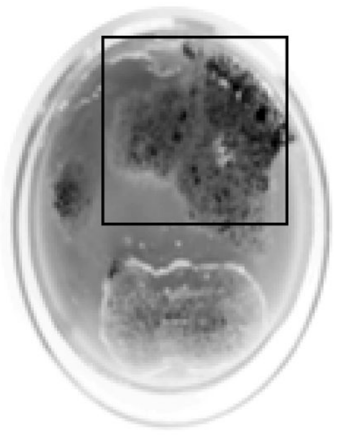

Control
Fig. 10 Comparison of different components plate of neem-coated Ag NPs showing an area of growth inhibition (arrow) of Aspergillus terreus, which is less than that of citrate-coated Ag NPs

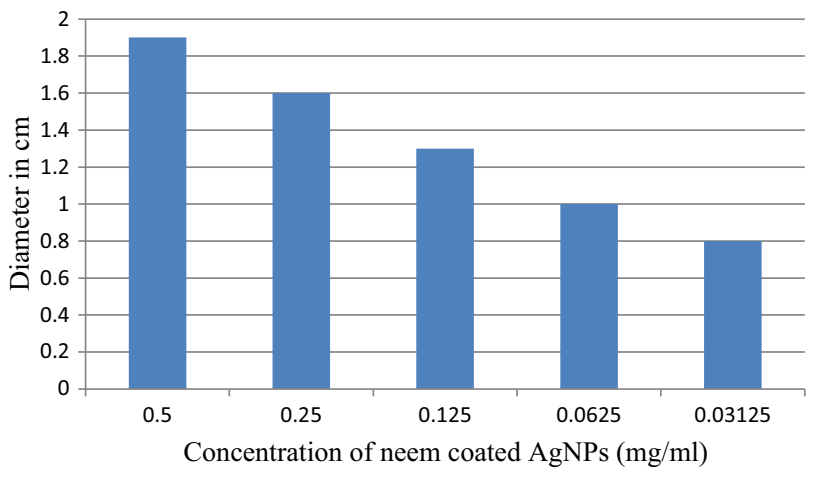

Fig. 11 Effect of neem-coated Ag NPs in terms of diameter of inhibition zone measured after 5 days at different concentrations on the growth of Aspergillus terreus

for $30 \mathrm{~min}$, and electronic absorption spectra were taken at 7-min time interval at a wave length ranging from 200 to $800 \mathrm{~nm}$.

\section{Procedure of seed germination}

Fifty seeds were washed by distilled water to clean the dust. Then, these seeds were soaked for $6 \mathrm{~h}$ in each solution of water, neem extracts, and citrate-coated Ag NPs, and neem-coated Ag NPs. Then, after $6 \mathrm{~h}$ of soaking, the seeds were put in Petri dishes with different concentrations of Ag NPs (five seeds in each Petri dish).

\section{Procedure for chlorophyll estimation}

Leaves were collected from 8-day-old seedling to estimate the chlorophyll content. Freshly cut leaves (40 mg) were weighed and put in $80 \%$ acetone for chlorophyll estimation. Chlorophyll a, chlorophyll b, and total chlorophyll were estimated following Arnon's method using the specific absorption coefficient given by Mackinney in 1941 $[18,19]$. The optical density (OD values) of the solutions was read at 645 and $663 \mathrm{~nm}$ using a Parkin Elmer UV-Vis spectrophotometer:

$$
\begin{aligned}
& \text { Chlorophylla }\left(\mathrm{mg} \mathrm{g}^{-1}\right) \\
& \quad=(12.7(\text { OD663 })-2.69(\text { OD645 })) \frac{V}{1000 \times W}
\end{aligned}
$$

Chlorophyll $\mathrm{b}\left(\mathrm{mg} \mathrm{g}^{-1}\right)$

$$
=(22.9(\text { OD645 })-4.68(\text { OD663 })) \frac{V}{1000 \times W}
$$

Total Chlorophyll $\left(\mathrm{mg} \mathrm{g}^{-1}\right)=(20.2($ OD645 $)+8.02($ OD663 $))$

where OD is the optical density, $V$ is the final volume of $80 \%$ acetone (i.e., $25 \mathrm{ml}$ ), and $W$ is the dry weight of sample taken (i.e., $40 \mathrm{mg}$ ).

\section{Procedure for antifungal study}

The $39 \mathrm{~g}$ of the potato dextrose with $3 \%$ agar was added in 11 of purified water followed by autoclaved at $121{ }^{\circ} \mathrm{C}$ for $15 \mathrm{~min} .10 \mathrm{ml}$ autoclaved medium was added in each Petri plate to let the medium solidify. The Petri plate was kept inside the incubator at $28^{\circ} \mathrm{C}$ for 1 day. After 1 day of incubation, the plates were checked to find out any contamination or not. Aspergillus terreus (from stock plate) was added in each plate for growth. After inoculation, the plate was kept at $28{ }^{\circ} \mathrm{C}$ inside the incubator for observation as per experimental requirements.

\section{Conclusions}

We have demonstrated that Ag NPs prepared by biogenic route using aqueous neem extract are less toxic compared with the conventional citrate-coated Ag NPs and an excellent antifungal material. This may be due to synergistic effects of antifungal activities of Ag NPs and aqueous extract of neem leaves. The present research primarily indicates possible application of neem-coated Ag NPs as a potential fungicide. 
Acknowledgments The authors gratefully acknowledge the support from the Head of the Department of Chemistry, NITA.

Author's contributions All authors have equally contributed to this study. All authors read and approved the final manuscript.

\section{Compliance with ethical standards}

Conflict of interest The authors declare that they have no competing interests.

Open Access This article is distributed under the terms of the Creative Commons Attribution 4.0 International License (http://crea tivecommons.org/licenses/by/4.0/), which permits unrestricted use, distribution, and reproduction in any medium, provided you give appropriate credit to the original author(s) and the source, provide a link to the Creative Commons license, and indicate if changes were made.

\section{References}

1. Abboud, Y., Eddahbi, A., Bouari, A.E., Aitenneite, H., Brouzi, K., Mouslim, J.: J. Nanostruct. Chem. 3(84), 1-7 (2013)

2. Tripathy, A., Raichur, A.M., Chandrasekaran, N., Prathna, T.C., Mukherjee, A.: Process variables in biomimetic synthesis of silver nanoparticles by aqueous extract of Azadirachta indica (Neem) leaves. J. Nanopart. Res. 12, 237-246 (2010)

3. Mazumdar, H.: The impact of silver nanoparticles on plant biomass and chlorophyll content. Int. J. Eng. Sci. 4(7), 12-20 (2014)

4. Dietz, K.J., Herth, S.: Plant nanotoxicology. Trends Plant Sci. 16, 582-589 (2011)

5. Klein, DA: Disposition and environmental impact of silver iodide in the National Hail Research Experiment: final report submitted to the National Center for Atmospheric Research, Publisher, Colorado State University (1978)

6. Farkhanda, M., Narjis, N., Malik, S.A., Siddiqui, B.S., Azka, S., Sobiya, P.: Chemical analysis and comparison of antitermitic activity of essential oils of neem (Azadirachta indica), vetiver (Vetiveria zizanioides) and mint (Mentha arvensis) against Heterotermesindicola (Wasmann) from Pakistan. Asian J. Chem. 24(5), 2069-2072 (2012)

7. Vinoth, B., Manivasagaperumal, R., Rajaravindran, M.: Phytochemical analysis and antibacterial activity of azadirachta indica a juss. Int. J. Res. Plant Sci. 2(3), 50-55 (2012)

8. James, W., Truman, W., Riddiford, L.M.: The temporal organization of the endocrine events underlying pupation of the tobacco hornworm. J. Exp. Biol. 60, 371-382 (1974)

9. Dai, J., Yaylayan, V.A., Raghavan, G.S., Parè, J.R.: Extraction and colorimetric determination of Azadirachtin-related limonoids in neem seed kernel. J. Agric. Food Chem. 47(9), 3738-3742 (1999)

10. Sharma, V., Walia, S., Kumar, J., Muraleedharan, G., Balraj, S.: An efficient method for the purification and characterization of nematicidal azadirachtins A, B, and $\mathrm{H}$, using MPLC and ESIMS. J Agric. Food Chem. 51, 3966-3972 (2003)

11. Khan, Z., Hussain, J.I., Hashmi, A.A.: Shape-directing role of cetyltrimethylammonium bromide in the green synthesis of $\mathrm{Ag}$ nanoparticles using neem (Azadirachta indica) leaf extract. Colloids Surf. B Biointerfaces 95, 229-234 (2012)

12. Alves, P.D., Brandão, M.G.L., Nunan, E.A., Vianna-Soares, C.D.: Chromatographic evaluation and antimicrobial activity of Neem (Azadirachta indica A. Juss., Meliaceae) leaves hydroalcoholic extracts, Brazilian. J. Pharmacogn. 19(2B), 510-515 (2009)

13. Lokanadhan, S., Muthukrishnan, P., Jeyaraman, S.: Neem products and their agricultural applications. J. Biopestic 5, 72-76 (2012)
14. Pankaj, S., Lowkeshwer, T., Mukesh, B., Vishnu, B.: Review on neem (Azadirachta indica): thouasand problem one solution. Int. Res. J. Pharm. 2(12), 97-102 (2011)

15. Xiu, Z.M., Ma, J., Alvarez, P.J.: Differential effect of common ligands and molecular oxygen on antimicrobial activity by silver nanoparticles versus silver ions. Environ. Sci. Technol. 45, 9003-9008 (2011)

16. Ogbuewu, I.P., Obeomenam, V.U., Obikaonu, H.O., Opara, M.N., Emenalom, O.O., Uchegbu, M.C., Okoli, I.C., Esonu, B.O., Iloeje, M.U.: The growth importance of Neem (Azadirachta indica A. Juss) in agriculture, industry, medicine and environment: a review. Res. J. Med. Plant 5(3), 230-245 (2011)

17. Yin, L., Colman, B.P., McGill, B.M., Wright, J.P., Bernhardt, E.S.: Effects of silver nanoparticle exposure on germination and early growth of eleven wetland plants. PLoS One 7(10), e47674(1)-e47674(7) (2012)

18. Lin, D.H., Xing, B.S.: Pytotoxicity of nanoparticles: inhibition of seed germination and root growth. Enyiro. Pollut. 150, 243-250 (2007)

19. Prabhu, S., Poulose, E.K.: Silver nanoparticles: mechanism of antimicrobial action, synthesis, medical applications and toxicity effects. Int. Nano Lett 2(32), 1-10 (2012)

20. Namratha, N., Monica, P.V.: Synthesis of silver nanoparticles using Azadirachta indica (neem) extract and usage in water purification. Asian J. Pharm. Tech. 3(4), 170-174 (2013)

21. Gavhane, A.J., Padmanabhan, P., Kamble, S., Jangle, S.: Synthesis of silver nanoparticles using extract of neem leaf and triphala and evaluation of their antimicrobial activities. Int J. Pharm. Bio. Sci. 3(3), 88-100 (2012)

22. Tripathy, A., Raichur, A.M., Chandrasekaran, N., Prathna, T.C., Mukherjee, A.: Anti bacterial application of silver nanoparticles synthesized by aqueous extract of Azadirachta Indica (neem) leaves. J. Biomed. Nanotechnol. 5, 93-98 (2009)

23. Lee, G.P., Bignell, L.J., Romeo, T.C., Razal, J.M., Shepherd, R.L., Chen, J., Minett, A.I., Innisa, P.C., Wallace, G.G.: The citrate-mediated shape evolution of transforming photomorphic silver nanoparticles. Chem. Commun. 46, 7807-7809 (2010)

24. Ahmed, E., Azeem, A., Elsayed, B.A.: Phytotoxicity of silver nanoparticles on Vicia faba seedlings. Int. J. Appl. Biol. Pharm Technol. 6(12), 148-156 (2013)

25. Wierzbicka, M., Obidzinska, J.: The effect of lead on seed inhibition and germination in different plant species. Plant Sci. 137, 155-171 (1998)

26. Hans, T.R.: Bioaccumulation and toxicity of silver compounds: a review. Environ. Toxicol. Chem. 18(1), 89-108 (1999)

27. Slade, S.J., Pegg, G.F.: The effect of silver and other metal ions on the in vitro growth of root-rotting Phytophthora and other fungal species. Ann Appl. Biol. 122(2), 233-251 (1993)

28. Yin, L., Colman, B.P., McGill, B.M., Wright, J.P., Bernhardt, E.S.: Effects of silver nanoparticle exposure on germination and early growth of eleven wetland plants. PLoS One 7(10), e476749 (2012)

29. Yin, L., Cheng, Y., Espinasse, B., Colman, B.P., Auffan, M., Wiesner, M., Rose, J., Liu, J., Bernhardt, E.S.: More than the ions: the effects of silver nanoparticles on lolium multiflorum. Environ. Sci. Technol. 45(6), 2360-2367 (2011)

30. Cheng, Y., Yin, L., Lin, S., Wiesner, M., Bernhardt, E., Liu, J.: Toxicity reduction of polymer-stabilized silver nanoparticles by sunlight. J. Phys. Chem. C 115(11), 4425-4432 (2011)

31. Sharma, P., Bhatt, D., Zaidi, M.H., Saradhi, P., Khanna, P.K., Arora, S.: Silver nanoparticle-mediated enhancement in growth and antioxidant status of Brassica juncea. Appl. Biochem. Biotechnol. 167, 2225-2233 (2012)

32. Das, S., Wolfson, B.P., Tetard, L., Tharkur, J., Bazataa, J., Santra, S.: Effect of N-acetyl cysteine coated CdS:Mn/ZnS quantum dots on seed germination and seedling growth of snow pea (Pisumsativum L.): imaging and spectroscopic studies. Environ. Sci. NANO 2, 203-212 (2015) 